CrossMark $\leftarrow$ click for update

Cite this: Dalton Trans., 2017, 46, 2609

Received 26th December 2016, Accepted 18th January 2017

DOI: $10.1039 / c 6 d t 04874 a$

rsc.li/dalton

\section{Sequence of phase transitions in $\left(\mathrm{NH}_{4}\right)_{3} \mathrm{SiF}_{7} \dagger$}

\author{
S. V. Mel'nikova, ${ }^{a}$ M. S. Molokeev, ${ }^{\star a, b}$ N. M. Laptash, ${ }^{c}$ E. I. Pogoreltsev, ${ }^{a, d}$ \\ S. V. Misyult: and I. N. Flerov ${ }^{a, d}$
}

\section{Introduction}

Silicon is the second most abundant element in the Earth's crust. Its double fluoride salt $\left(\mathrm{NH}_{4}\right)_{3} \mathrm{SiF}_{7}=\left(\mathrm{NH}_{4}\right)_{3} \mathrm{SiF}_{7} \cdot \mathrm{NH}_{4} \mathrm{~F}=$ $\left(\mathrm{NH}_{4}\right)_{3}\left[\mathrm{SiF}_{6}\right] \mathrm{F}$ is the main product of fluoride processing of natural silicon-containing raw materials (quartz and silicates of different structure and compositions) with ammonium hydrogen difluoride $\left(\mathrm{NH}_{4} \mathrm{HF}_{2}\right){ }^{1-5}$ Fluorination reactions proceed exothermally (even at room temperature) with an entropy reserve. Elemental silicon also interacts with $\mathrm{NH}_{4} \mathrm{HF}_{2}$ with the formation of $\left(\mathrm{NH}_{4}\right)_{3} \mathrm{SiF}_{7}{ }^{6,7}$ It is accepted in the literature that this salt was first prepared by Marignac in $1859 .{ }^{8} \mathrm{He}$ obtained it in the form of square prisms from aqueous fluoride solution. However, similar shape ('tetrahedral prisms') crystals were observed by Davy as early as $1812 .{ }^{9}$ The crystal structure of $\left(\mathrm{NH}_{4}\right)_{3} \mathrm{SiF}_{7}$ was studied in 1942 by Hoard and Williams ${ }^{10}$ and solved using oscillation photographs. In spite of the measurements being performed very carefully and the final model crystal structure being adequate, the authors reported large discrepancies between the calculated and observed reflection amplitudes. They associated these discrepancies with the fluorine anions, for which large temperature corrections should be performed, and pointed out that it

\footnotetext{
${ }^{a}$ Laboratory of Crystal Physics, Kirensky Institute of Physics, Federal Research Center KSC SB RAS, Krasnoyarsk, 660036, Russia. E-mail: msmolokeev@mail.ru

${ }^{b}$ Department of Physics, Far Eastern State Transport University, Khabarovsk, 680021, Russia

${ }^{c}$ Institute of Chemistry, Far Eastern Branch of RAS, Vladivostok, 690022, Russia

${ }^{d}$ Siberian Federal University, Krasnoyarsk, 660074, Russia

$\dagger$ Electronic supplementary information (ESI) available. CSD 432220-432223. For ESI and crystallographic data in CIF or other electronic format see DOI: 10.1039/ c6dt04874a

$\$$ S. V. Misyul unfortunately died while this manuscript was in the process of being published.
}

would be of interest to obtain diffraction data for $\left(\mathrm{NH}_{4}\right)_{2} \mathrm{SiF}_{6} \cdot \mathrm{NH}_{4} \mathrm{~F}$ at liquid air temperatures. This task has not been performed until now. Moreover, no data on phase transitions in this compound are available in the literature.

Recently, we found that the isostructural compound $\left(\mathrm{NH}_{4}\right)_{3} \mathrm{GeF}_{7}$ (space group $\mathrm{P} 4 / \mathrm{mbm}$ ) underwent several reversible phase transitions below room temperature with an unusual sequence $P 4 / \mathrm{mbm} \leftrightarrow P b a m \leftrightarrow P 2_{1} / c \leftrightarrow P a \overline{3} .{ }^{11}$ Moreover, some other fluoride double salts $\left(\mathrm{NH}_{4}\right)_{3} \mathrm{M}^{4+} \mathrm{F}_{7}\left(\mathrm{M}^{4+}=\mathrm{Ti}^{4+}, \mathrm{Sn}^{4+}\right)$ undergo phase transitions but of different sequences, and a correlation with the $\mathrm{M}^{4+}$ ionic radius was found. ${ }^{11-16}$ Therefore, one might expect the temperature variation would also destabilise the room temperature structure of the silicon double fluoride salt, leading to phase transitions.

In the present paper, a complex study of $\left(\mathrm{NH}_{4}\right)_{3} \mathrm{SiF}_{7}$ using optical, X-ray, and calorimetric measurements revealed that the succession of structural transformations differs from the sequences observed earlier by us in other related compounds $\left(\mathrm{NH}_{4}\right)_{3} \mathrm{M}^{4+} \mathrm{F}_{7}$. The crystal structures of all the phases were solved and a reliable model of structural distortions associated with certain order parameters was suggested.

\section{Experimental}

\subsection{Synthesis and crystal growth}

Single crystals of a double salt $\left(\mathrm{NH}_{4}\right)_{3} \mathrm{SiF}_{7}$ were grown from aqueous fluoride solution with an excess of $\mathrm{NH}_{4} \mathrm{~F}$ or $\mathrm{NH}_{4} \mathrm{HF}_{2}$. Solid $\mathrm{SiO}_{2},\left(\mathrm{NH}_{4}\right)_{2} \mathrm{SiF}_{6}, \mathrm{NH}_{4} \mathrm{~F}$ and $\mathrm{NH}_{4} \mathrm{HF}_{2}$ of a reagent grade were used. Silicon dioxide (amorphous or quartz) was fluorinated with $\mathrm{NH}_{4} \mathrm{HF}_{2}$ at $150-200{ }^{\circ} \mathrm{C}$ in a Pt or glass-carbon beaker. It should be noted that the reaction began at room temperature itself while grinding together the initial components. A double excess, at least, of $\mathrm{NH}_{4} \mathrm{HF}_{2}$ was taken rela- 
tive to the stoichiometric reaction: $\mathrm{SiO}_{2}+3.5 \mathrm{NH}_{4} \mathrm{HF}_{2}=$ $\left(\mathrm{NH}_{4}\right)_{3} \mathrm{SiF}_{7}+0.5 \mathrm{NH}_{3}+2 \mathrm{H}_{2} \mathrm{O}$. The cake obtained in this way was then water-leached, filtered and colourless prismatic single crystals of $\left(\mathrm{NH}_{4}\right)_{3} \mathrm{SiF}_{7}$ were formed by slow evaporation of the final solution under ambient conditions. The crystals were recovered by vacuum filtration and air-dried. A large excess of $\mathrm{NH}_{4} \mathrm{~F}$ was needed to obtain $\left(\mathrm{NH}_{4}\right)_{3} \mathrm{SiF}_{7}$ in the $\mathrm{NH}_{4} \mathrm{~F}-$ $\left(\mathrm{NH}_{4}\right)_{2} \mathrm{SiF}_{6}-\mathrm{H}_{2} \mathrm{O}$ system. ${ }^{17}$ We used a triple excess relative to the stoichiometric reaction: $\left(\mathrm{NH}_{4}\right)_{2} \mathrm{SiF}_{6}+\mathrm{NH}_{4} \mathrm{~F}=\left(\mathrm{NH}_{4}\right)_{3} \mathrm{SiF}_{7}$. For example, $20 \mathrm{~g}$ of $\left(\mathrm{NH}_{4}\right)_{2} \mathrm{SiF}_{6}$ and 12-15 $\mathrm{g}$ of $\mathrm{NH}_{4} \mathrm{~F}$ were mixed and dissolved in $100 \mathrm{ml}$ of deionised water, filtered and slowly evaporated at ambient temperature with the formation of transparent tetragonal prisms. It is not surprising that Davy had observed similar crystals during the addition of excess ammonia to hexafluorosilicic acid ('the subsilicated fluoric acid'). ${ }^{9}$

\subsection{Calorimetric investigations}

The temperature stability of the initial tetragonal phase $\mathrm{P} 4 / \mathrm{mbm}$ of $\left(\mathrm{NH}_{4}\right)_{3} \mathrm{SiF}_{7}$ was examined by measurements with a DSM-10M differential scanning microcalorimeter (DSM). Recently it has been shown that among fluorides $\left(\mathrm{NH}_{4}\right)_{3} \mathrm{M}^{4+} \mathrm{F}_{7}$ there are at least two crystals undergoing a phase transition into the cubic phase $P m \overline{3} m$ above room temperature at ambient - $\left(\mathrm{NH}_{4}\right)_{3} \mathrm{SnF}_{7}{ }^{13}$ - or high $-\left(\mathrm{NH}_{4}\right)_{3} \mathrm{TiF}_{7}{ }^{16}$ - pressure. Therefore the thermal investigations were performed in a wide temperature range of 100-460 $\mathrm{K}$.

A sample of the powdered compound under study was placed into an aluminium sample holder. Calorimetric measurements were carried out under a helium atmosphere on several samples with a mass of about 0.03-0.06 g. In order to gain information on the hysteretic phenomena associated with the probable structural transformations in $\left(\mathrm{NH}_{4}\right)_{3} \mathrm{SiF}_{7}$, experiments were carried out using heating and cooling runs with a rate of temperature change $\mathrm{d} T / \mathrm{d} \tau$ of 8 to $32 \mathrm{~K} \mathrm{~min}^{-1}$. The calibration of the temperature and enthalpy scales was performed using the melting parameters of pure indium as well as tabulated data of enthalpy against temperature for $\mathrm{Al}_{2} \mathrm{O}_{3}$. The temperature was determined with an accuracy of $\pm 1 \mathrm{~K}$ and the uncertainty on the enthalpy and entropy values was estimated to be $\pm 5 \mathrm{~J} \mathrm{~mol}^{-1}$ and $\pm 0.1 \mathrm{~J} \mathrm{~mol}^{-1} \mathrm{~K}^{-1}$, respectively.

\subsection{Optical observations}

Optical studies were performed using a polarizing microscope (Axioskop-40) and a Linkam LTS 350 temperature chamber. The investigations were carried out in a quasi-static regime with an accuracy of $\pm 0.1 \mathrm{~K}$ in the range of $90-400 \mathrm{~K}$. The birefringence was measured using a Berek compensator (Leica) with an accuracy of $\approx 0.00001$.

\subsection{X-ray investigations}

Optical experiments proved a complex microtwinning of the crystal under cooling. Currently it seems impossible to solve or refine the crystal structure by single crystal diffraction due to the complex picture of overlapping peaks from different domains. Moreover, a resolution of the single crystal experiment is worse than that of the powder diffraction. Subtle changes of cell parameters can be appropriately investigated by only using a powder diffraction technique, which was chosen in our case.

The powder diffraction data of $\left(\mathrm{NH}_{4}\right)_{3} \mathrm{SiF}_{7}$ for Rietveld analysis were collected with a Bruker D8 Advance powder diffractometer ( $\mathrm{Cu}-\mathrm{K} \alpha$ radiation) and a linear VANTEC detector. The beam was controlled by a $0.6 \mathrm{~mm}$ fixed divergence slit, $6 \mathrm{~mm}$ receiving VANTEC slit and Soller slits. An Anton Paar TTK450 attachment was used for low- and high-temperature measurements.

The diffraction data in the $2 \theta$ range $5^{\circ}$ to $120^{\circ}$ were collected at $T=303 \mathrm{~K}, T=213 \mathrm{~K}, T=183 \mathrm{~K}$, and $T=133 \mathrm{~K}$ (Fig. 1S $\dagger$ ). These X-ray patterns were used to solve and refine the crystal structures. Eighteen additional X-ray patterns with smaller exposition time were collected from $133 \mathrm{~K}$ to $303 \mathrm{~K}$ to identify the space group transformation at phase transition.

The crystal structures of the low-temperature phases were solved by a distortion-mode refinement of X-ray data using the TOPAS $4.2^{18}$ program, with a file generated by ISODISPLACE. Amplitudes of critical symmetry-modes were used to find a structural model by the simulated anneal method. Then all atomic coordinates were refined independently by the Rietveld method. Isotropic thermal parameters of $\mathrm{Si}$ atoms were refined independently, but all $\mathrm{F}$ atoms as well as $\mathrm{N}$ atoms had one thermal parameter.

\section{Results and discussion}

\subsection{Calorimetry}

No anomalous behaviour of the DSM-signal was observed in experiments above room temperature until the decomposition $(\sim 450 \mathrm{~K})$ of $\left(\mathrm{NH}_{4}\right)_{3} \mathrm{SiF}_{7}$. Below room temperature, calorimetric studies revealed four anomalies reproducible in the heating and cooling runs, which were suggested to be associated with the successive phase transitions $\mathrm{G}_{1}\left(T_{1}\right) \leftrightarrow \mathrm{G}_{2}\left(T_{2}\right) \leftrightarrow \mathrm{G}_{3}\left(T_{3}\right) \leftrightarrow$ $\mathrm{G}_{4}\left(T_{4}\right) \leftrightarrow \mathrm{G}_{5}$. The background of the DSM-signal $(T)$ dependence, considered to be the lattice contribution into the total DSM-signal, was extracted by polynomial approximation of the experimental data far from the anomalous regions. The quantity determined as the difference between the total DSM-signal and its lattice component is associated with the excess molar heat capacity $\Delta C_{\mathrm{p}}$ connected with the order parameters of transformations which will be discussed below.

Fig. 1a depicts the temperature dependence of $\Delta C_{\mathrm{p}}$ for one of the samples obtained in experiments with $\mathrm{d} T / \mathrm{d} \tau=8$ $\mathrm{K} \min ^{-1}$. The behavior of $\Delta C_{\mathrm{p}}$ at the transformation $\mathrm{G}_{1} \leftrightarrow \mathrm{G}_{2}$ is typical for the second order: a small asymmetric anomaly characterised by a broad temperature range of the $\Delta C_{\mathrm{p}}$ existence below $T_{1}=263 \pm 1 \mathrm{~K}$, which was detected as the temperature of the $\Delta C_{\mathrm{p}}$ maximum. A significant hysteresis in the transition temperatures $T_{2}, T_{3}$, and $T_{4}$ as well as its strong dependence on the heating/cooling rate was observed during the thermal cycling. These experimental facts confirm that trans- 


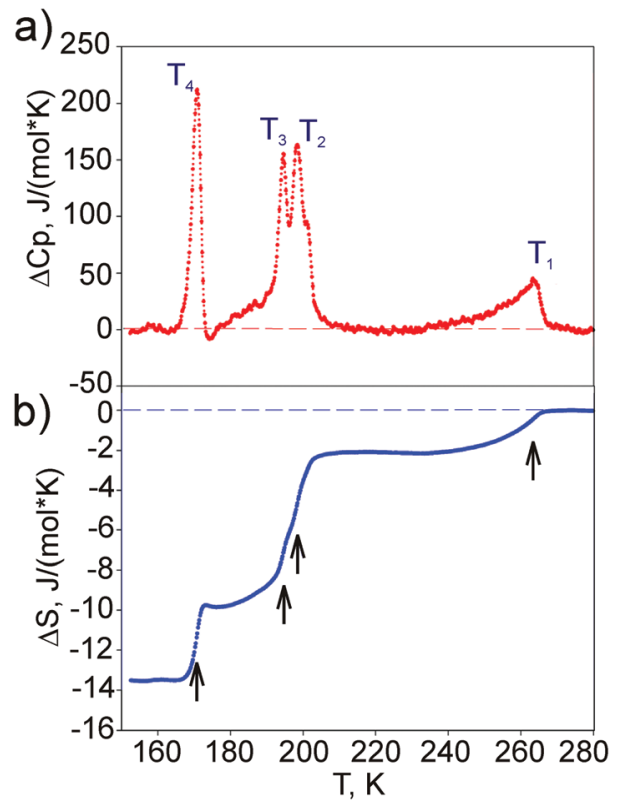

Fig. 1 Temperature dependences of the excess heat capacity (a) and entropy (b) associated with the successive phase transitions $G_{1} \leftrightarrow G_{2} \leftrightarrow$ $\mathrm{G}_{3} \leftrightarrow \mathrm{G}_{4} \leftrightarrow \mathrm{G}_{5}$.

formations $\mathrm{G}_{2} \leftrightarrow \mathrm{G}_{3} \leftrightarrow \mathrm{G}_{4} \leftrightarrow \mathrm{G}_{5}$ are of the first order. Analysis of the $T_{i}$ dependence on $\mathrm{d} T / \mathrm{d} \tau$ in the heating and cooling modes allowed the determination of the real values of phase transition temperatures and their hysteresis, which were considered as parameters under equilibrium conditions when $\mathrm{d} T / \mathrm{d} \tau \rightarrow 0: T_{2}=198 \pm 1 \mathrm{~K}, \delta T_{2}=1 \mathrm{~K} ; T_{3}=194 \pm 1 \mathrm{~K}, \delta T_{3}=2 \mathrm{~K} ;$ $T_{4}=170 \pm 1 \mathrm{~K}, \delta T_{4}=5 \mathrm{~K}$.

The entropy change associated with the successive phase transitions was determined by integration of the $\left(\Delta C_{\mathrm{p}} / T\right)(T)$ function. Fig. 1b depicts the temperature behaviour of entropy. Its total value associated with the succession of phase transitions $\mathrm{G}_{1} \leftrightarrow \mathrm{G}_{2} \leftrightarrow \mathrm{G}_{3} \leftrightarrow \mathrm{G}_{4} \leftrightarrow \mathrm{G}_{5}$ is rather large: $\sum \Delta S_{i}=13.6 \pm$ $3.0 \mathrm{~J} \mathrm{~mol}^{-1} \mathrm{~K}^{-1}$, revealing some order-disorder process in the mechanism of structural distortions. Because a DSM technique is not sensitive to the small excess heat capacity which can exist far below the phase transition point, we did not discuss the value of $\Delta S_{i}$ for individual transformations. For this we plan to perform a more detailed study of heat capacity using an adiabatic calorimeter.

Thus, the calorimetric measurements have shown that the cationic substitution $\mathrm{Si} \rightarrow$ Ge in compounds $\left(\mathrm{NH}_{4}\right)_{3} \mathrm{M}^{4+} \mathrm{F}_{7}$ is accompanied by a small broadening of the temperature range of the $P 4 / \mathrm{mbm}$ phase stability $\left(T_{1}=280 \mathrm{~K}\right.$ in $\left.\left(\mathrm{NH}_{4}\right)_{3} \mathrm{GeF}_{7}\right)$ and an increase in the number of the phase transformations. ${ }^{11}$

\subsection{Polarization optics}

The single crystals of $\left(\mathrm{NH}_{4}\right)_{3} \mathrm{SiF}_{7}$, like $\left(\mathrm{NH}_{4}\right)_{3} \mathrm{GeF}_{7}$, have a habitus of elongated rectangular prisms with the developed facets of (110) $\mathrm{t}$. The four-fold axis is preferably located along the longest edge of the crystal, so the plate-like sample with a $(001)_{t}$ orientation is very rare. Two of these samples are pre-
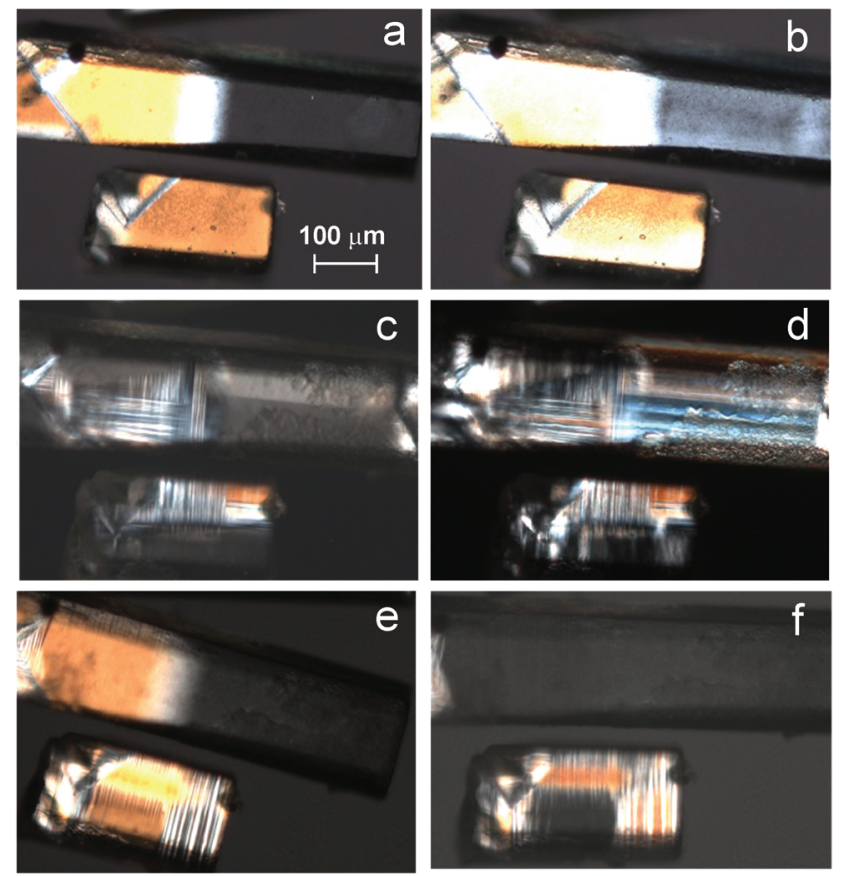

Fig. 2 Observation of crystals $\left(\mathrm{NH}_{4}\right)_{3} \mathrm{SiF}_{7}$ under polarized light upon cooling: (a) phase $G_{1}$, (b) $G_{2}$, (c) $G_{3}$, (d) $G_{4}$, (e and f) $G_{5}$. The upper sample consists of two blocks with different orientations of the fourfold axis in the $G_{1}$ phase, the lower plate has a $(110)_{t}$ orientation.

sented in Fig. 2. The upper crystal consists of two blocks. The left side of this sample has an orientation (110)t, and extinction along the growth edges. The right-hand block side $\left(\Delta n_{\mathrm{c}}=\right.$ $0)$ is optically isotropic and has an orientation of (001)t. The uniaxial pressure increase (up to destruction of the sample) did not change the orientation of the fourth-order axis in $\left(\mathrm{NH}_{4}\right)_{3} \mathrm{SiF}_{7}$, similar to that found earlier for $\left(\mathrm{NH}_{4}\right)_{3} \mathrm{GeF}_{7} \cdot{ }^{11}$ Thus, silicon and germanium compounds differ from $\left(\mathrm{NH}_{4}\right)_{3} \mathrm{TiF}_{7}$, where small uniaxial pressure reoriented this axis at 90 degrees. $^{15}$

Fig. 2 presents photographs of the $\left(\mathrm{NH}_{4}\right)_{3} \mathrm{SiF}_{7}$ plates as grown in polarised light. At room temperature the right-hand side of the upper sample is dark; and the left side has a 'direct extinction' in accordance with a tetragonal symmetry $\left(\mathrm{G}_{1}\right.$ phase) (Fig. 2a). Upon cooling the pattern changes significantly. Below $T_{1 \downarrow}=263 \mathrm{~K}$ the dark area of the sample illuminates (Fig. 2b). The entire crystal illuminates completely or extinguishes along the growth verge $(110)_{t}$ when the microscope stage is rotated by $90^{\circ}\left(\mathrm{G}_{2}\right.$-phase).

Further cooling leads to the appearance (disappearance) at $T_{2 \downarrow}=198 \mathrm{~K}\left(T_{2 \uparrow}=199 \mathrm{~K}\right)$ of a layered structure with boundaries along $[110]_{\mathrm{t}}$ in the left-hand block (Fig. 2c). Optical indicatrices in the neighbouring twins are disoriented to the direction $[110]_{\mathrm{t}}$. In the right-hand part of the specimen the direct extinction remains.

Upon cooling below $T_{3 \downarrow}=191 \mathrm{~K}\left(T_{3 \uparrow}=192 \mathrm{~K}\right)$, the specimen shows a very complicated twin structure in three orthogonal directions with a 'floating' position of extinctions (Fig. 2d). 


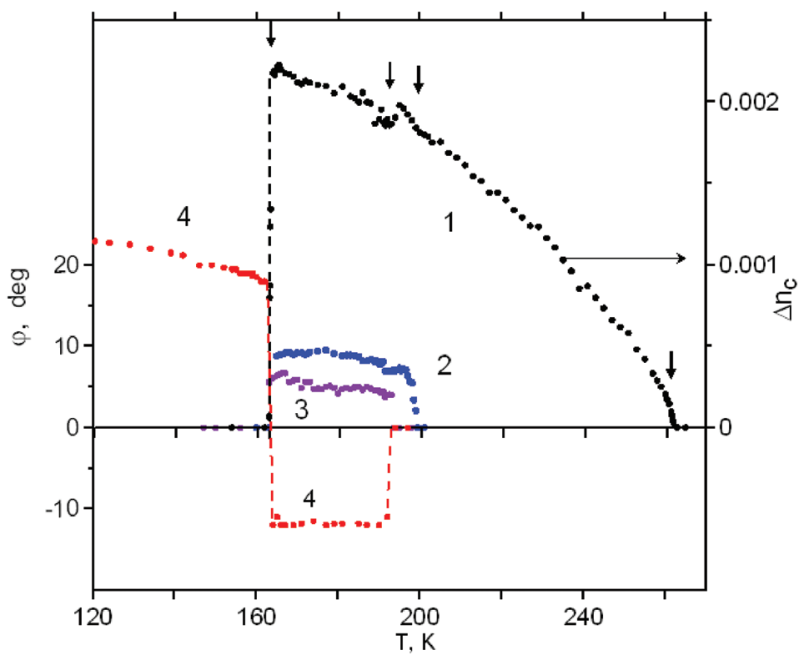

Fig. 3 The appearance of optical anisotropy in the plate $(001)_{\mathrm{t}}$ at $T_{1}$ and its change at $T_{2}, T_{3}, T_{4}$ : curve $1-\Delta n_{c}(T)$. The rotation of the optical indicatrix around $[110]_{t}$ and $[001]_{t}$ directions: curve $2-\varphi_{\mathrm{a}}(T)$; curve $3-\varphi_{\mathrm{c}}(T)$; curve $4-\varphi_{\mathrm{b}}(T)$.

Further cooling reveals an abrupt phase transition at $T_{4 \downarrow}=$ $162 \mathrm{~K}\left(T_{4 \uparrow}=167 \mathrm{~K}\right)$ into the tetragonal phase with, at first glance, a dark right side (Fig. 2e). But in contrast to the initial tetragonal phase (Fig. 2a) in the twins with coexistence, 'direct' (Fig. 2f), or 'oblique' (Fig. 2e) extinctions are observed in the lower $(110)_{\mathrm{t}}$ plate.

The illumination of the dark area of the sample below $T_{1 \downarrow}=$ $263 \mathrm{~K}$ (Fig. 2b) is associated with a reduction of crystal symmetry and the appearance of optical anisotropy along the $[001]_{\mathrm{t}}$ direction. Fig. 3 shows the temperature behaviour of the $\Delta n_{\mathrm{c}}$ birefringence, which appears at $T_{1}$ and smoothly changes near $T_{2}$ and $T_{3}$, while at $T_{4}$ there is a sharp disappearance of $\Delta n_{\mathrm{c}}$.

The twin structure in very thin plates $(\sim 50 \mu \mathrm{m})$ consists of rather large domains in the phase $\mathrm{G}_{5}$ which allows measurement of the temperature dependence of the birefringence $\Delta n(T)$ and the angle of rotation of the optical indicatrix $\varphi(T)$ (Fig. 4).

At room temperature the main birefringence of tetragonal $\left(\mathrm{NH}_{4}\right)_{3} \mathrm{SiF}_{7}\left(\Delta n=n_{\mathrm{o}}-n_{\mathrm{e}}=0.0037\right)$ is higher than that in $\left(\mathrm{NH}_{4}\right)_{3} \mathrm{GeF}_{7}\left(\Delta n=0.0034\right.$ (ref. 11)) and $\left(\mathrm{NH}_{4}\right)_{3} \mathrm{TiF}_{7}(\Delta n=0.0023$ (ref. 12)). Fig. 4 shows that the birefringence in the phase $\mathrm{G}_{1}$ of $\left(\mathrm{NH}_{4}\right)_{3} \mathrm{SiF}_{7}$ is stable, varying slightly with temperature and gradually decreasing below $T_{1}$.

The DSM and polarization-optical studies as well as measuring the birefringence and the rotation angles of the indicatrix in the $\left(\mathrm{NH}_{4}\right)_{3} \mathrm{SiF}_{7}$ crystal allowed the establishment of the existence of four structural phase transitions between the $G_{1}, G_{2}, G_{3}, G_{4}$ and $G_{5}$ phases, with different symmetries. According to the temperature dependences of DSM and optical characteristics (Fig. 1, 3 and 4), the character of transitions in $\left(\mathrm{NH}_{4}\right)_{3} \mathrm{SiF}_{7}$ is the following: the second order for $\mathrm{G}_{1} \leftrightarrow \mathrm{G}_{2}$, and first order close to the tricritical point for $G_{2} \leftrightarrow G_{3} \leftrightarrow G_{4}$. Therefore, we assume that a successive lowering of crystal sym-

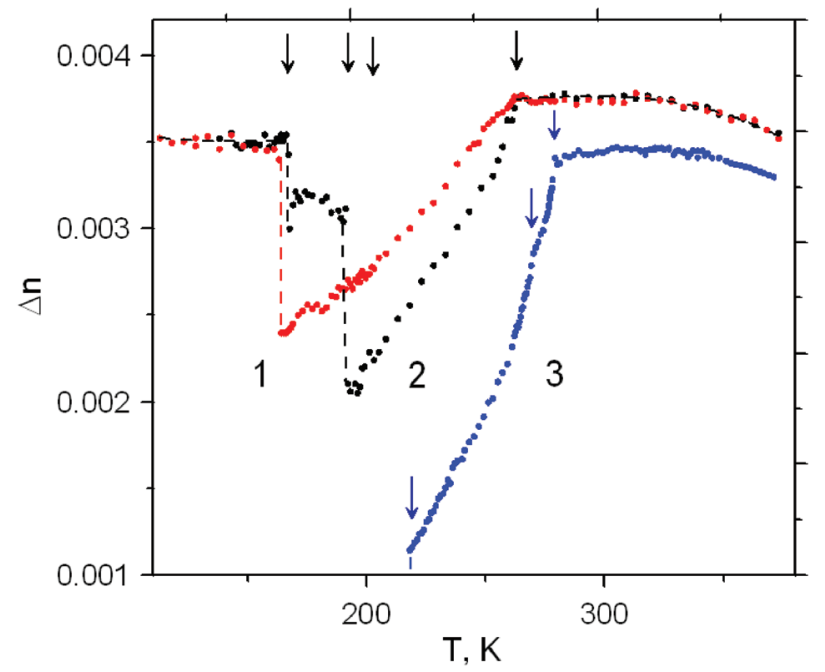

Fig. 4 Temperature dependence of birefringence $\Delta n(T)$ of the crystal $\left(\mathrm{NH}_{4}\right)_{3} \mathrm{SiF}_{7}$ in the plate $(110)_{\mathrm{t}}$, measured during cooling (curve 1) and heating (curve 2). Curve 3 is $\Delta n(T)$ in $\left(\mathrm{NH}_{4}\right)_{3} \mathrm{GeF}_{7}{ }^{11}$

metry taking place through three phase transitions at $T_{1}, T_{2}$, and $T_{3}$ can be described in the framework of group-subgroup relationships.

The presence of the optical anisotropy $\Delta n_{\mathrm{c}}$ and the position of extinction along the $[110]_{\mathrm{t}}$ direction reveals the geometry of a new cell in the $G_{2}$ phase. The group symmetry of that phase is most likely orthorhombic. Two axes of the unit cell should be perpendicular to the 4 -fold axis and directed along the unit cell diagonals of the tetragonal $\mathrm{G}_{1}$ phase: $[110]_{\mathrm{t}}=[010]_{\mathrm{or}}$; $[110]_{\mathrm{t}}=[100]_{\mathrm{or}} ;[001]_{\mathrm{t}}=[001]_{\mathrm{or}}$.

The geometry of twinning and rotation of the optical indicatrix only around the $[110]_{\mathrm{t}}=[100]_{\text {or }}$ direction indicates the symmetry of the $G_{3}$ phase to be monoclinic $P 2_{1} / c 11$. The screw twofold axis is perpendicular to the former four-fold axis and directed along $[100]_{\text {or }}$ of an orthorhombic unit cell of the $G_{2}$ phase. Thus, the successive lowering of symmetry during phase transitions at $T_{1}$ and $T_{2}$ was established, similar to that observed in $\left(\mathrm{NH}_{4}\right)_{3} \mathrm{GeF}_{7}: P 4 / \mathrm{mbm}\left(\mathrm{G}_{1}\right) \leftrightarrow \operatorname{Pbam}\left(\mathrm{G}_{2}\right) \leftrightarrow$ $P 2_{1} / c\left(\mathrm{G}_{3}\right){ }^{11}$

Further temperature lowering leads to an additional cooling decrease in the symmetry of $\left(\mathrm{NH}_{4}\right)_{3} \mathrm{SiF}_{7}$ at $T_{3}$. It can be seen (Fig. 3) that the angle of rotation $\varphi_{\mathrm{a}}$ is maintained at the lower phase $\mathrm{G}_{4}$, which is added by the rotation $\varphi_{\mathrm{b}}(T)$ and $\varphi_{\mathrm{c}}(T)$ around different axes of the orthorhombic unit cell. Therefore, the crystal symmetry group in this phase can be selected as triclinic $P \overline{1}$.

The phase transition $\mathrm{G}_{4} \leftrightarrow \mathrm{G}_{5}$ has a first-order character: there are rapid jumps of extinction angles and birefringence values (Fig. 3). At first glance, the sample in the bottom phase $\mathrm{G}_{5}$ looks similar to that at room temperature: right-hand dark side $\left(\Delta n_{\mathrm{c}}=0\right)$ and orange interference colour on the left-hand side (Fig. 2e). All optical data indicate the crystal identification to be tetragonal. However, in the $(110)_{t}$ plane the observed twins have different positions of extinction. Simultaneous 'direct' and 'oblique' extinctions are observed (Fig. 2e and f). 
Thus, the crystal symmetry group in the $G_{5}$ phase can be chosen as monoclinic. The above studies show the difference between the monoclinic phases $G_{3}$ and $G_{5}$, with respect to a two-fold axis. This axis is directed along $[110]_{\mathrm{t}}=[100]_{\text {or }}$ in $\mathrm{G}_{3}$, but along $[110]_{\mathrm{t}}=[010]_{\text {or }}$ in $\mathrm{G}_{5}$.

Thus, the polarisation-optical studies suggest the existence of a rather complicated sequence of crystal symmetry changes upon cooling: $P 4 / \mathrm{mbm}\left(\mathrm{G}_{1}\right) \leftrightarrow \operatorname{Pbam}\left(\mathrm{G}_{2}\right) \leftrightarrow P 2_{1} / c 11\left(\mathrm{G}_{3}\right) \leftrightarrow P \overline{1}$ $\left(\mathrm{G}_{4}\right) \leftrightarrow P 12_{1} / c 1\left(\mathrm{G}_{5}\right)$.

A shear deformation with component $x_{4}$ (within the orthorhombic cell) appears in phase $\mathrm{G}_{3}$, causing rotation of the optical indicatrix on the angle $\varphi_{\mathrm{a}}$ (Fig. 3, curve 2). Additional components of shear deformation $x_{5}$ and $x_{6}$ appear in the triclinic $\mathrm{G}_{4}$ phase, causing the indicatrix rotation $\varphi_{\mathrm{b}}$ and $\varphi_{\mathrm{c}}$ (Fig. 3, curves 3, 4). A further temperature lowering results in the formation of the monoclinic phase $G_{5}$, where the components $x_{4}$ and $x_{6}$ disappear and $x_{5}$ remains, changing its sign (Fig. 3, curve 4). An unusually large angle of indicatrix rotation $\varphi_{\mathrm{b}} \approx 25^{\circ}$ is characteristic of the 'proper' ferroelastic transitions when a parameter of transition $\delta$ is linearly related to the shear component of the spontaneous deformation $\delta \approx x_{5}$.

\subsection{X-ray diffraction and group theory analysis}

As the crystal structure of $\left(\mathrm{NH}_{4}\right)_{3} \mathrm{SiF}_{7}$ at room temperature was solved earlier, ${ }^{10}$ we used this model $(P 4 / \mathrm{mbm})$ to make a Rietveld refinement by using TOPAS 4.2. ${ }^{18}$ The refinement was stable and gave low $R$-factors (Table 1 and Fig. $1 \mathrm{~S}(\mathrm{a}) \dagger$ ). Atomic coordinates are given in Table $1 S, \dagger$ main bond lengths are given in Table 2, and the crystal structure is presented in Fig. 5a. The compound $\left(\mathrm{NH}_{4}\right)_{3} \mathrm{SiF}_{7}$ was found to be very pure and all lines were indexed by the $P 4 / \mathrm{mbm}$ phase (Fig. 1S(a) $\dagger$ ). Cell parameters after refinement were close to those from ref. 11.

One can see (Fig. 6 and 7a) that the first wave of superstructure peaks appears at $T=253 \mathrm{~K}$. This temperature is $10 \mathrm{~K}$ lower than $T_{1}=263 \mathrm{~K}$. This is because the powder sample in an X-ray experiment is cooled from the bottom, while diffrac- tion happens only from the top surface, and the result is a temperature gradient in the powder sample. This temperature difference was further taken into account to make measurements in all other experiments. Additional peaks appearing at $253 \mathrm{~K}$ can be described by the emergence of instability at $(1 / 2$, $1 / 2,0) k_{18}$-point $(M)$ of the Brillouin zone of the $\mathrm{G}_{1}-P 4 / \mathrm{mbm}$ unit cell (hereinafter the designation of irreducible representations (irrep) and points of the Brillouin zone are given in accordance with reference books). ${ }^{19,20}$ The observation of a similar situation in $\left(\mathrm{NH}_{4}\right)_{3} \mathrm{GeF}_{7}{ }^{11}$ allowed the conclusion that the mechanism of $\mathrm{G}_{1} \leftrightarrow \mathrm{G}_{2}$ transformation in germanium and silicon compounds should be the same. The $M_{1}{ }^{-} \oplus M_{4}{ }^{-}$irrep drives this phase transition, and the transformation can be written: $P 4 / \mathrm{mbm}^{M_{1}-\oplus M_{4}^{-}\left(\eta_{1}, \eta_{2}\right)}$ Pbam, where $\eta_{1}$ and $\eta_{2}$ are components of critical order parameters. The crystal structure for the Rietveld refinement in TOPAS 4.2 was prepared by the ISODISTORT program using the initial $\mathrm{G}_{1}$ phase $(P 4 / \mathrm{mbm})$ and $M_{1}{ }^{-} \oplus M_{4}{ }^{-}$irrep distortion. The refinement was stable and gave low $R$-factors (Table 1 and Fig. $1 \mathrm{~S}(\mathrm{~b}) \dagger$ ). Atomic coordinates are given in Table $1 \mathrm{~S}, \dagger$ main bond lengths are given in Table 2 and the crystal structure is presented in Fig. 5b.

Group-theoretical analysis showed that in $\left(\mathrm{NH}_{4}\right)_{3} \mathrm{SiF}_{7}$, similarly to $\left(\mathrm{NH}_{4}\right)_{3} \mathrm{GeF}_{7}$, the $\mathrm{MF}_{6}(\mathrm{M}=\mathrm{Si}, \mathrm{Ge})$ octahedron was split $\left(\mathrm{MF}_{6} \rightarrow \mathrm{M} \mathrm{F}_{6}+\mathrm{M}_{2} \mathrm{~F}_{6}\right)$ at phase transition $\mathrm{P} 4 / \mathrm{mbm} \leftrightarrow$ Pbam. The critical irrep $M_{1}{ }^{-} \oplus M_{4}{ }^{-}$induces the greatest contribution to distortions and leads to the critical shift of fluorine ions along the $a$ and $b$ axes of the orthorhombic phase. These movements can be represented as rotation of the $\mathrm{MF}_{6}$ octahedron around the 4-fold axis in the tetragonal phase (Fig. 8a and $\mathrm{b}$ ). The $\mathrm{F}-\mathrm{N}$ bond lengths vary in the range of 2.907(3)3.109(3) A in the tetragonal phase to 2.77(2)-3.23(1) A (Table 2) in the orthorhombic phase. The decrease of these bond lengths may be due to the formation of $\mathrm{N}-\mathrm{H} \cdots \mathrm{F}$ hydrogen bonds. Since $\mathrm{SiF}_{6}$ octahedra are ordered in the $\mathrm{G}_{1}$ phase while $\mathrm{NH}_{4}$ tetrahedra are disordered due to a high local symmetry of one $\mathrm{NH}_{4}$ site $(4 / \mathrm{m})$, the transformation $\mathrm{P} 4 / \mathrm{mbm} \leftrightarrow$ Pbam can be associated only with the ordering of $\mathrm{NH}_{4}$ groups. The for-

Table 1 Main parameters of processing and refinement of the $\left(\mathrm{NH}_{4}\right)_{3} \mathrm{SiF}_{7}$ sample in four phases

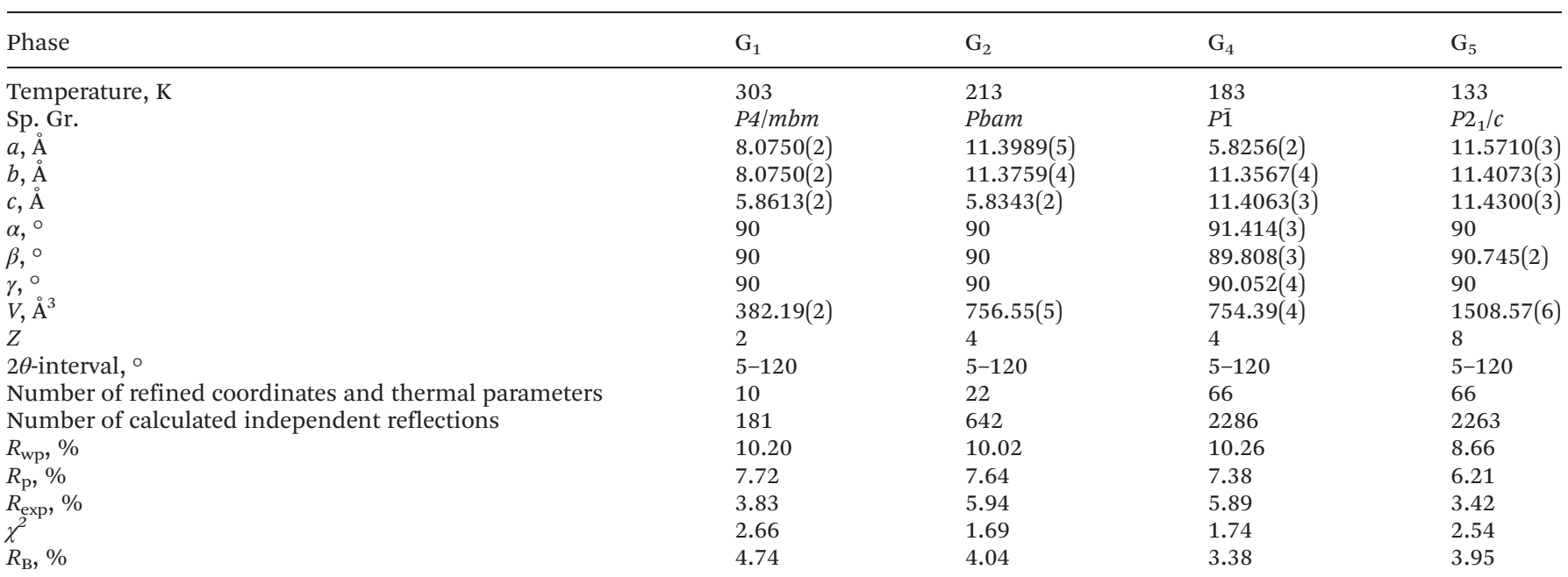


Table 2 Main bond lengths $(\AA)$ in the four phases of $\left(\mathrm{NH}_{4}\right)_{3} \mathrm{SiF}_{7}$

\begin{tabular}{|c|c|}
\hline$P 4 / m b m\left(\mathrm{G}_{1}\right.$ & $T=303$ \\
\hline $\mathrm{Si} 1-\mathrm{F} 2 \times 2$ & $1.623(3)$ \\
\hline $\mathrm{N} 1-\mathrm{F} 1 \times 2$ & $2.9307(1$ \\
\hline $\mathrm{N} 2-\mathrm{F} 3 \times 2$ & $2.848(4)$ \\
\hline $\mathrm{N} 2-\mathrm{F} 2 \times 2$ & $3.009(1)$ \\
\hline $\operatorname{Pbam}\left(\mathrm{G}_{2} \mathrm{ph}\right.$ & $=213 \mathrm{~K}$ \\
\hline Si1-F3 $\times 2$ & 1.71(1) \\
\hline $\mathrm{Si} 2-\mathrm{F} 2 \times 2$ & $1.636(9)$ \\
\hline N1-F3 & $2.77(2)$ \\
\hline $\mathrm{N} 1-\mathrm{F} 1 \times 2$ & $2.9207(7$ \\
\hline N2-F1 & $2.88(2)$ \\
\hline N2-F1 & $2.94(2)$ \\
\hline N3-F5 × 2 & 2.81(1) \\
\hline N3-F4 × 2 & $2.88(1)$ \\
\hline$P \overline{1}\left(\mathrm{G}_{4}\right.$ phas & $183 \mathrm{~K}$ \\
\hline Si1-F3 × 2 & 1.66(1) \\
\hline Si1-F9 × 2 & $1.63(2)$ \\
\hline Si1-F13 $\times 2$ & $1.73(2)$ \\
\hline $\mathrm{Si} 2-\mathrm{F} 4 \times 2$ & $1.61(2)$ \\
\hline $\mathrm{Si} 2-\mathrm{F} 10 \times 2$ & $1.78(2)$ \\
\hline Si2-F14 $\times 2$ & $1.60(2)$ \\
\hline N1-F6 & 2.81(3) \\
\hline N1-F1 & $2.92(5)$ \\
\hline N1-F7 & $3.02(3)$ \\
\hline N2-F5 & $2.69(3)$ \\
\hline N2-F4 & $2.93(3)$ \\
\hline N2-F8 & $3.01(3)$ \\
\hline N3-F2 & $2.68(3)$ \\
\hline N3-F13 & $2.82(3)$ \\
\hline N3-F3 & $2.92(4)$ \\
\hline N4-F8 & $2.73(4)$ \\
\hline N4-F1 & $2.77(3)$ \\
\hline N4-F4 & $2.98(4)$ \\
\hline N5-F12 & $2.68(3)$ \\
\hline N5-F6 & $2.77(4)$ \\
\hline $\mathrm{N} 5-\mathrm{F9}^{\mathrm{v}}$ & 2.91(4) \\
\hline N6-F2 & $2.72(3)$ \\
\hline N6-F11 & $2.80(3)$ \\
\hline N6-F5 & \\
\hline
\end{tabular}

N6-F5

2.97(4)

$P 2_{1} / c$ ( $\mathrm{G}_{5}$ phase) at $T=133 \mathrm{~K}$

Si1-F7 $\times 2 \quad 1.66(1)$

Si1-F9 $\times 2 \quad 1.75(1)$

$\mathrm{Si} 2-\mathrm{F} 6 \times 2 \quad 1.68(1)$

$\mathrm{Si} 2-\mathrm{F} 8 \times 2$

Si2-F10 $\times 2 \quad 1.71(1)$

N1-F5

N1-F11

$2.83(2)$

N1-F1

$2.87(2)$

N2-F1

$2.90(2)$

$2.76(2)$

$2.88(2)$

$3.02(2)$

$\mathrm{N} 3-\mathrm{F} 2 \quad 2.73(3)$

N3-F12 2.89(2)

N3-F7 2.96(2)

N4-F8 2.69(2)

N4-F14 2.80(2)

N4-F13 3.01(2)

N5-F2 2.72(2)

N5-F9 2.80(2)

N5-F6 2.87(3)

N6-F2 2.60(2)

N6-F7 2.93(2)

N6-F11

N1-F2

$\mathrm{N} 1-\mathrm{F} 5 \times 2$

$\mathrm{N} 2-\mathrm{F} 4 \times 2$

$\mathrm{N} 2-\mathrm{F} 2 \times 2$

N3-F1

N3-F1

Si3-F6 $\times 2$

Si3-F8 $\times 2$

Si3-F12 $\times 2$

Si4-F5 $\times 2$

Si4-F7 × 2

Si4-F11 $\times 2$

N1-F1

N1-F10

N1-F3

N2-F2

N2-F2

N2-F3

N3-F7

N3-F11

N3-F1

N4-F10

N4-F12

N4-F14

N5-F2

N5-F13

N5-F8

N6-F10

N6-F14

N6-F1

Si3-F3 $\times 2$

Si3-F11 $\times 2$

Si3-F13 $\times 2$

Si4-F4 $\times 2$

Si4-F12 $\times 2$

$\mathrm{Si} 4-\mathrm{F} 14 \times 2$

$\mathrm{N} 1-\mathrm{F} 3$

N1-F7

N1-F2

N2-F4

N2-F10

N2-F6

N3-F10

N3-F4

N3-F3

N4-F1

N4-F9

N4-F4

N5-F12

N5-F8

N5-F13

N6-F14

N6-F6

N6-F10

$3.01(3)$

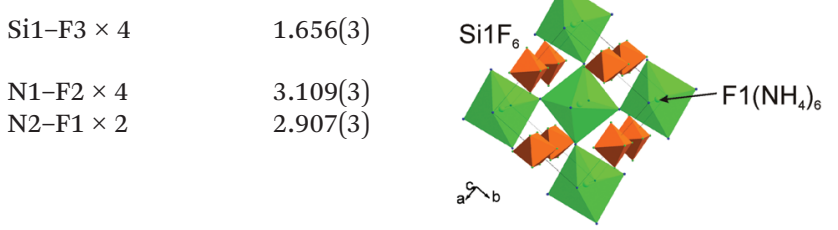

a) $P 4 / m b m\left(G_{1}\right.$ phase $)$

$\begin{array}{ll}\text { Si1-F } 4 \times 4 & 1.624(7) \\ \text { Si2-5 } \times 4 & 1.691(7)\end{array}$

2.84(2)

$3.23(1)$

2.93(1)

2.998(4)

$2.82(2)$

$2.97(2)$

$1.71(2)$

$1.69(2)$

$1.65(2)$

$1.78(2)$

$1.68(2)$

$1.70(2)$

2.91(5)

2.94(3)

$3.11(3)$

$2.88(5)$

$2.98(5)$

$3.17(3)$

$2.76(3)$

$2.88(3)$

$2.96(3)$

$2.75(3)$

$2.95(3)$

$3.01(3)$

$2.77(3)$

$2.90(3)$

$3.02(4)$

$2.76(3)$

$2.85(3)$

$3.01(3)$

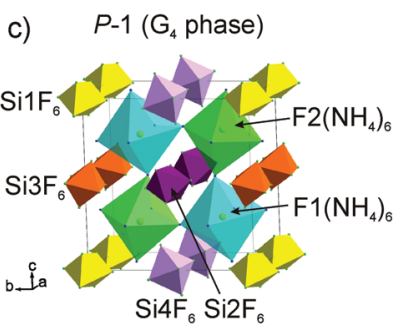
(d) $G_{5}$ phase $\left(P 2_{1} / C\right)$ at $T=133 \mathrm{~K}$. from $133 \mathrm{~K}$ to $303 \mathrm{~K}$.

$1.58(1)$

$1.57(2)$

$1.67(1)$

1.79(1)

$2.84(2)$

2.89(2)

$3.06(2)$

2.85(2)

3.02(2)

$3.16(2)$

$2.78(2)$

2.95(3)

$3.00(3)$

2.72(3)

2.88(2)

3.01(3)

2.79(2)

2.84(2)

2.94(2)

$2.73(2)$

2.97(3)

3.06(2) this phase is monoclinic.

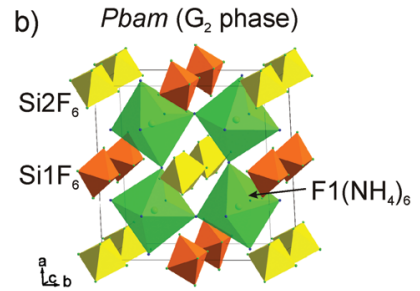

Fig. 5 Crystal structures of $\left(\mathrm{NH}_{4}\right)_{3} \mathrm{SiF}_{7}$ : (a) $\mathrm{G}_{1}$ phase $(P 4 / \mathrm{mbm})$ at $T=$ $303 \mathrm{~K}$; (b) $\mathrm{G}_{2}$ phase $(P b a m)$ at $T=213 \mathrm{~K}$, (c) $\mathrm{G}_{4}$ phase $(P \overline{1})$ at $T=183 \mathrm{~K}$;

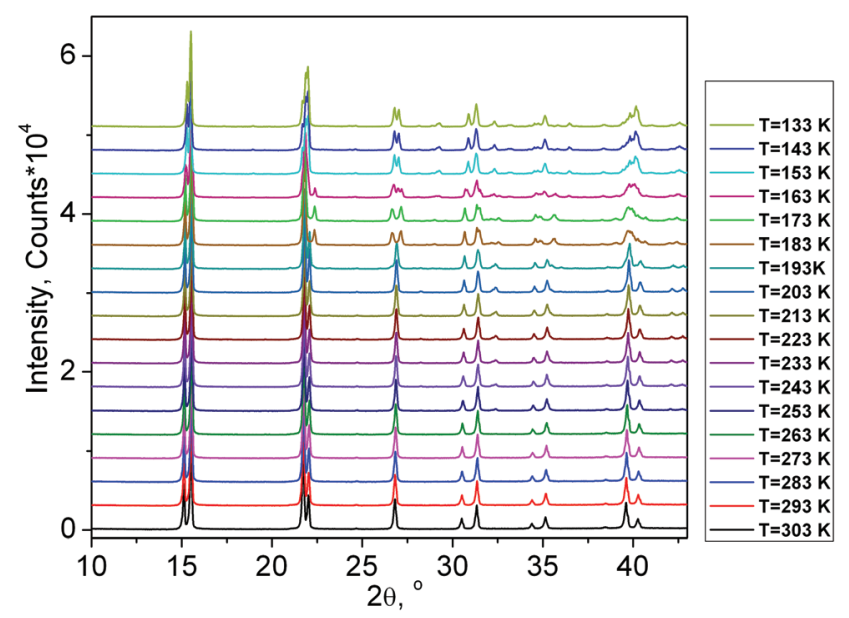

Fig. $6 \mathrm{X}$-ray powder patterns of $\left(\mathrm{NH}_{4}\right)_{3} \mathrm{SiF}_{7}$ at different temperatures

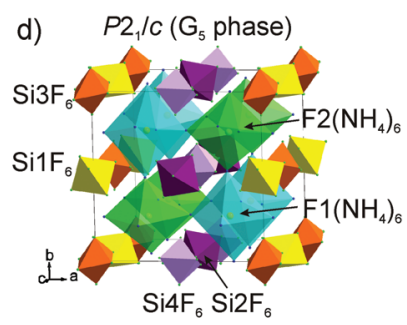

mation of hydrogen bonds (short $\mathrm{N} \cdots \mathrm{F}$ contacts) after phase transition may serve as an indicator of $\mathrm{NH}_{4}$ ordering.

It was impossible to carry out the X-ray measurements in the $\mathrm{G}_{3}$ phase due to the narrow temperature region of its existence. However, it was found from optical measurements that

The X-ray experiment in of the $\mathrm{G}_{4}$ phase (Fig. $1 \mathrm{~S}(\mathrm{c}), \dagger$ Fig. 6 and $7 \mathrm{~b}$ ) reveals that the main peak broadening occurs, but there are no additional superstructure peaks (Fig. 7a); therefore it can be concluded that the $G_{3} \leftrightarrow G_{4}$ phase transition is associated with the emergence of instability at the same $(1 / 2$, $1 / 2,0) k_{18}$-point (M) of the Brillouin zone of $P 4 / \mathrm{mbm}$. Optical investigations showed a triclinic symmetry of this phase. The space group $P \overline{1}$ with basis of a tetragonal $G_{1}$ phase $(0,0,1),(1,1,0),(-1,1,0)$ fulfills all these conditions. 

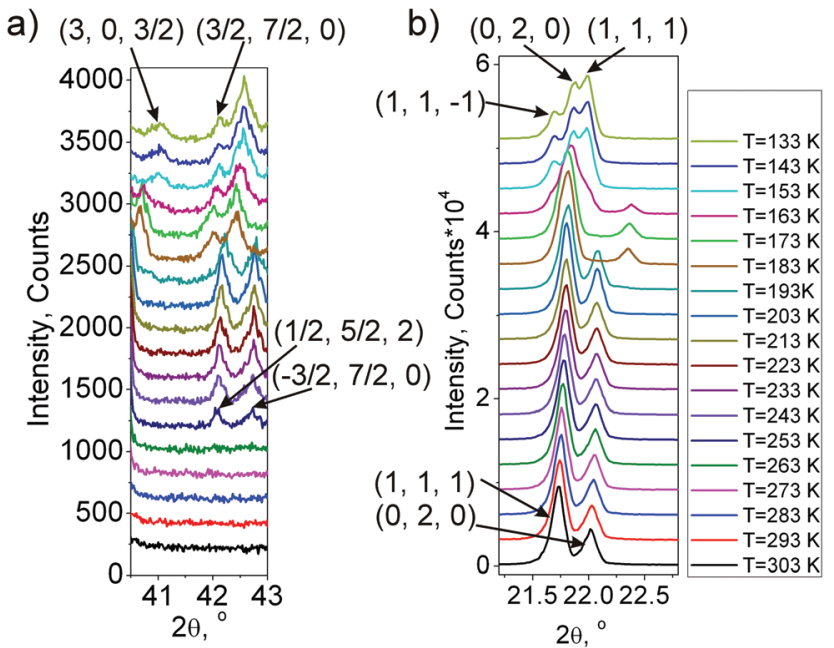

Fig. 7 Fragment of $\mathrm{X}$-ray powder patterns of $\left(\mathrm{NH}_{4}\right)_{3} \mathrm{SiF}_{7}$ with: (a) superstructure peaks $(3,0,3 / 2)$ and $(1 / 2,5 / 2,2)$, which are prohibited in the $\mathrm{G}_{1}$ tetragonal phase $(P 4 / \mathrm{mbm}) ;(b)$ structure peaks $(1,1,1)$ and $(0,2,0)$ of the $\mathrm{G}_{1}$ tetragonal phase.

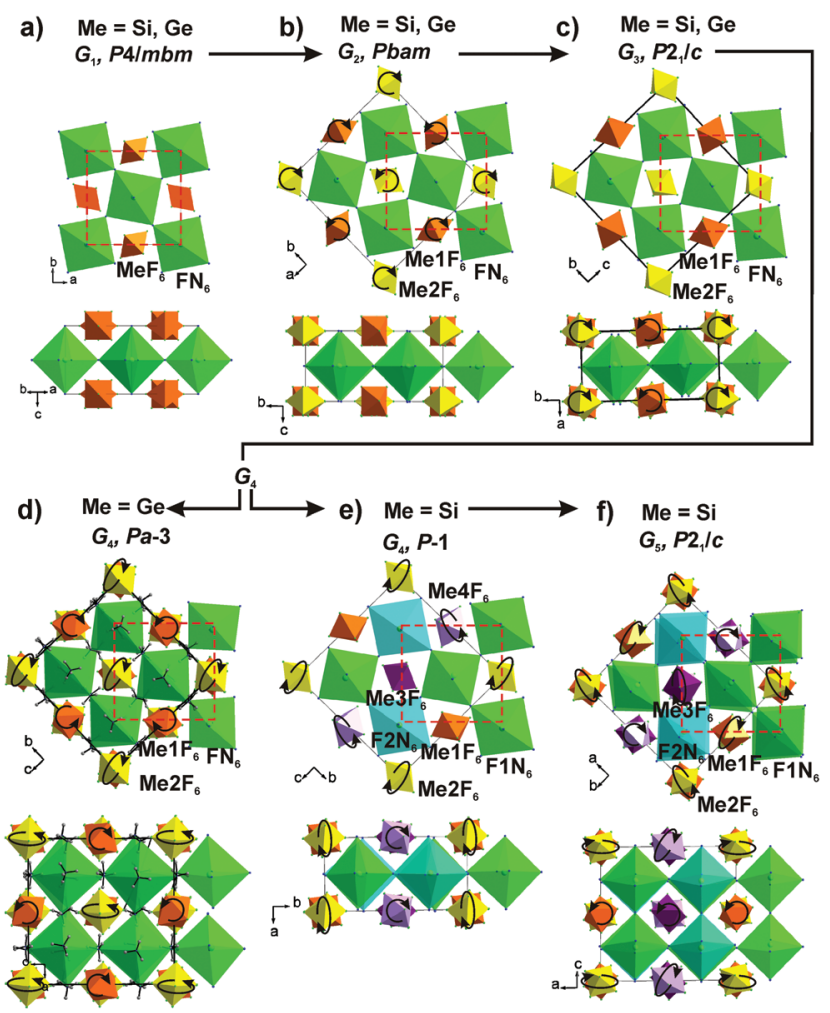

Fig. 8 The main distortions of the $\left(\mathrm{NH}_{4}\right)_{3} \mathrm{MeF}_{7}(\mathrm{Me}=\mathrm{Si}, \mathrm{Ge})$ crystal structures at phase transitions, leading to rotation of $\mathrm{MF}_{6}$ octahedra during the transformations in different projections. Dashed red rectangle surrounds the formula unit of different phases. The sequence of $G_{1} \leftrightarrow$ $\mathrm{G}_{2} \leftrightarrow \mathrm{G}_{3}$ of the phases is the same for both $\left(\mathrm{NH}_{4}\right)_{3} \mathrm{SiF}_{7}$ and $\left(\mathrm{NH}_{4}\right)_{3} \mathrm{GeF}_{7}$, but their $G_{3} \leftrightarrow G_{4}$ phase transitions are different. Further $G_{4} \leftrightarrow G_{5}$ transition exists only in $\left(\mathrm{NH}_{4}\right)_{3} \mathrm{SiF}_{7}$.
The $M_{1}{ }^{-} \oplus M_{4}{ }^{-}$and $M_{5}{ }^{-}$irreps drive this phase transition and the transformation can be written as:

$$
\begin{aligned}
& \mathrm{P} 4 / \mathrm{mbm} \stackrel{M_{1}-\oplus M_{4}^{-}\left(\eta_{1}, \eta_{2}\right)}{\longleftrightarrow} \text { Pbam }
\end{aligned}
$$

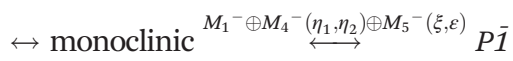

where $(\xi, \varepsilon)$ are other critical order parameters, which are transformed according to $M_{5}{ }^{-}$irrep of the sp. gr. $P 4 / \mathrm{mbm}$. The crystal structure for Rietveld refinement in TOPAS 4.2 was prepared by the ISODISTORT program using $M_{5}{ }^{-}$irrep distortion. Refinement was stable and gave low $R$-factors (Table 1 and Fig. $1 \mathrm{~S}(\mathrm{c}) \dagger$ ). Atomic coordinates are presented in Table $1 \mathrm{~S}, \uparrow$ main bond lengths are given in Table 2, and the crystal structure is shown in Fig. 5c. It should be noted that slightly different order parameters of $M_{5}{ }^{-}$irrep, namely $(\xi, \xi)$, drive $P 4 / \mathrm{mbm}$ to the $P 2_{1} / c$ phase. Such a phase transition was found in $\left(\mathrm{NH}_{4}\right)_{3} \mathrm{GeF}_{7}$. Since the phase transition $\mathrm{G}_{1} \leftrightarrow \mathrm{G}_{2}$ in both compounds $\left(\mathrm{NH}_{4}\right)_{3} \mathrm{M}^{4+} \mathrm{F}_{7}\left(\mathrm{M}^{4+}=\mathrm{Si}, \mathrm{Ge}\right)$ is the same, and $M_{1}{ }^{-} \oplus M_{4}{ }^{-}$ with $M_{5}^{-}$irreps drive $\mathrm{G}_{2} \leftrightarrow \mathrm{G}_{3}$ and $\mathrm{G}_{3} \leftrightarrow \mathrm{G}_{4}$ transitions, the sequence of phase transitions in $\left(\mathrm{NH}_{4}\right)_{3} \mathrm{SiF}_{7}$ is suggested:

$$
\begin{aligned}
& P 4 / m b m \stackrel{M_{1}-\oplus M_{4}^{-}\left(\eta_{1}, \eta_{2}\right)}{\longleftrightarrow} P b a m \stackrel{M_{1}^{-} \oplus M_{4}^{-}\left(\eta_{1}, \eta_{2}\right) \oplus M_{5}^{-}(\xi, \xi)}{\longleftrightarrow} \\
& P 2_{1} / c \stackrel{M_{1}^{-} \oplus M_{4}^{-} \stackrel{\left(\eta_{1}, \eta_{2}\right)}{\longrightarrow} \oplus M_{5}^{-}(\xi, \varepsilon)}{\longrightarrow} \overline{1} .
\end{aligned}
$$

So we can imagine that the main rotations of $\mathrm{SiF}_{6}$ and $\mathrm{GeF}_{6}$ octahedra during $\mathrm{G}_{2} \leftrightarrow \mathrm{G}_{3}$ phase transition are the same (Fig. 8c). After this transformation all similarities between $\left(\mathrm{NH}_{4}\right)_{3} \mathrm{SiF}_{7}$ and $\left(\mathrm{NH}_{4}\right)_{3} \mathrm{GeF}_{7}$ vanish. Under $\mathrm{G}_{3} \leftrightarrow \mathrm{G}_{4}$ transition $\left(\mathrm{NH}_{4}\right)_{3} \mathrm{SiF}_{7}$ shows transformation $P 2_{1} / c \leftrightarrow P \overline{1}$ (Fig. 8e), but $\left(\mathrm{NH}_{4}\right)_{3} \mathrm{GeF}_{7}$ showed reconstructive phase transition $P 2_{1} / c \leftrightarrow P a \overline{3}$ (Fig. 8d). Previously it was found that all $\mathrm{NH}_{4}$ groups in the $\mathrm{Pa} \overline{3}$ phase of $\left(\mathrm{NH}_{4}\right)_{3} \mathrm{GeF}_{7}$ are ordered and all hydrogen atoms were localized. The crystal structure of the $P \overline{1}$ phase of $\left(\mathrm{NH}_{4}\right)_{3} \mathrm{SiF}_{7}$ shows several rather short $\mathrm{F}-\mathrm{N}$ bonds: $d(\mathrm{~N} 2 \cdots \mathrm{F} 5)=2.69(3) \AA, d(\mathrm{~N} 3 \cdots \mathrm{F} 2)=2.68(3) \AA, d(\mathrm{~N} 4 \cdots \mathrm{F} 8)=2.73(4) \AA$, and the range of $\mathrm{F}-\mathrm{N}$ distances expands to 2.68(3)-3.17(3) $\AA$ (Table 2), which indicates the presence of $\mathrm{N}-\mathrm{H} \cdots \mathrm{F}$ hydrogen bonds. However, the smallest contact over all N1 $\cdots \mathrm{F}$ contacts, $d(\mathrm{~N} 1 \cdots \mathrm{F} 6)=$ 2.81(3) $\AA$, is not very short for a H-bond, therefore some $\mathrm{NH}_{4}$ disordering could remain in the crystal structure.

Indeed, below $T_{4}$, a new phase $\mathrm{G}_{5}$ in $\left(\mathrm{NH}_{4}\right)_{3} \mathrm{SiF}_{7}$ was observed, and an additional wave of superstructure peaks appeared (Fig. 6 and 7a). All these new peaks can be described by the emergence of instability at $(0,0,1 / 2) k_{19}$-point $(Z)$ of the Brillouin zone of the $\mathrm{G}_{1}-P 4 / \mathrm{mbm}$ unit cell. Indexing shows that a cell in the $G_{5}$ phase becomes $P 2_{1} / c$ with twice the cell volume compared to the $\mathrm{G}_{4}$ phase $(P \overline{1})$. The $M_{1}{ }^{-} \oplus M_{4}{ }^{-}, M_{5}{ }^{-}$and $Z_{1}^{+}$irreps drive this phase transition, and the transformation can be written as: $P 4 / m b m ~ \stackrel{M_{1}^{-} \oplus M_{4}^{-}\left(\eta_{1}, \eta_{2}\right) \oplus M_{5}^{-}(\xi, \xi) \oplus Z_{1}^{+}(\delta)}{\longleftrightarrow} P 2_{1} / c$, where $\delta$ is a component of the critical order parameter. Cell parameters and the volume of the $\mathrm{G}_{5}$ phase $\left(P 2_{1} / c\right)\left(\mathrm{NH}_{4}\right)_{3} \mathrm{SiF}_{7}$ (Table 1 and Fig. 8f) finally became similar to those of the $\mathrm{G}_{4}$ phase $(\mathrm{Pa} \overline{3})$ in $\left(\mathrm{NH}_{4}\right)_{3} \mathrm{GeF}_{7}$ (ref. 11, Fig. 8d). The crystal structure $\mathrm{G}_{5}$ of $\left(\mathrm{NH}_{4}\right)_{3} \mathrm{SiF}_{7}$ for Rietveld refinement in TOPAS 4.2 was prepared by the ISODISTORT program using the initial $\mathrm{G}_{1}$ phase $(P 4 / \mathrm{mbm})$ and $M_{1}{ }^{-} \oplus M_{4}{ }^{-}, M_{5}{ }^{-}, Z_{1}{ }^{+}$irreps distortion. There are 
30 amplitude modes which should be initially varied and their starting values should be found before Rietveld refinement. A simulated annealing procedure in TOPAS 4.2 was used, and a satisfactory model with low $R$-factors was obtained. The refinement of the obtained model was stable and gave low $R$-factors (Table 1 and Fig. $1 \mathrm{~S}(\mathrm{~d}) \dagger$ ). Atomic coordinates are given in Table 1S; $\dagger$ the crystal structure is shown in Fig. $5 \mathrm{~d}$. The F-N distances are in the range of 2.60(2)-3.17(2) $\AA$ and indicate the formation of $\mathrm{N}-\mathrm{H} \cdots \mathrm{F}$ hydrogen bonds. In comparison with the $\mathrm{G}_{4}$ phase their average values become smaller, and it seems that all $\mathrm{NH}_{4}$ groups are ordered in the $\mathrm{G}_{5}$ phase.

It is easy to see that the phase $\mathrm{G}_{1}(\mathrm{P} 4 / \mathrm{mbm})$ (Fig. 8a), in fact, can be represented as a rotationally distorted antiperovskite $\mathrm{ABX}_{3},{ }^{21}$ where $\mathrm{A}=\left[\mathrm{SiF}_{6}\right], \mathrm{B}=[\mathrm{F}]$ and $\mathrm{X}=\left[\mathrm{NH}_{4}\right]$, i.e. $\left[\mathrm{SiF}_{6}\right][\mathrm{F}]\left[\mathrm{NH}_{4}\right]_{3}$. The cubic $P m \overline{3} m$ phase is a parent phase of antiperovskite $^{21}$ (Fig. 9a), which is not realized in our case. However, taking $P m \overline{3} m$ as a parent phase, the analysis of sequential orientation changes of $\mathrm{F}\left(\mathrm{NH}_{4}\right)_{6}$ octahedra at phase transitions was performed. It should be noted that $\mathrm{SiF}_{6}$ were not taken into consideration because they were isolated and didn't form a system of linked octahedra. Therefore, using Glazer's notation $^{22}$ (Fig. 9b) for the system of linked octahedral $\mathrm{F}\left(\mathrm{NH}_{4}\right)_{6}$, the following scheme was found:

$$
\begin{gathered}
P m \overline{3} m \stackrel{a^{0} a^{0} c^{+}}{\longrightarrow} P 4 / m b m \stackrel{a^{0} a^{0} c^{+}}{\longrightarrow} P b a m \stackrel{a^{0} b^{-} c^{+}}{\longrightarrow} \\
P 2_{1} / c \stackrel{a^{0} b^{-} c^{+}}{\longrightarrow} P \overline{1} \stackrel{a^{0} b^{-} c^{+}}{\longrightarrow} P 2_{1} / c
\end{gathered}
$$

where $a^{0}$ means an absence of any octahedral rotation, $c^{+}$ means in-phase octahedral rotation in all layers along the

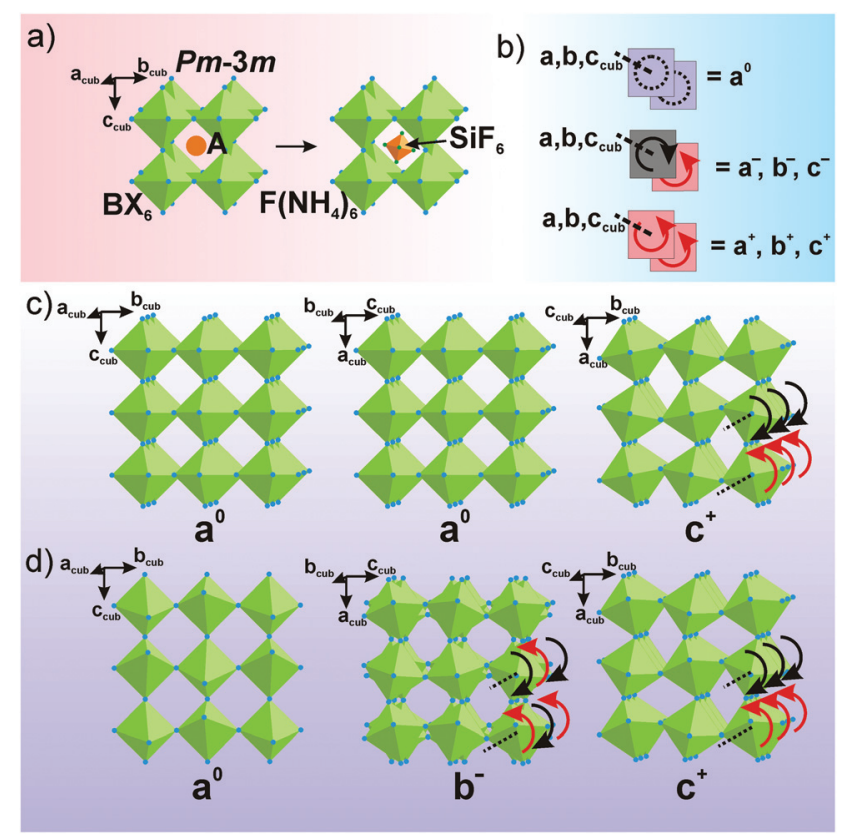

Fig. 9 Relationship between perovskite-type structure and antiperovskite parent $P m \overline{3} m\left(\mathrm{G}_{0}\right)$ phase of $\left[\mathrm{SiF}_{6}\right][\mathrm{F}]\left[\mathrm{NH}_{4}\right]_{3}(\mathrm{a})$. All possible octahedral tilts in neighboring layers of perovskites and corresponding Glazer's notations (b). Rotation of $\mathrm{F}\left(\mathrm{NH}_{4}\right)_{6}$ octahedra in $a^{0} a^{0} c^{+}$(c) and $a^{0} b^{-} c^{+}$(d), which are realized under phase transitions. $c$-axis, $b^{-}$means antiphase rotation along the $b$-axis in the neighboring layers. The value of the $\mathrm{F}\left(\mathrm{NH}_{4}\right)_{6}$ rotation angle, which is associated with $c^{+}$, is approximately equal to $\sim 10.9^{\circ}$, but rotation angles associated with $b^{-}$are an order of magnitude lower and equal $\sim 1.4^{\circ}$. Schemes of the $a^{0} a^{0} c^{+}$and $a^{0} b^{-} c^{+}$ tilt systems are shown in Fig. 9c and d, where rotation values are artificially increased for clarity. Despite the fact that the tilt systems are the same for several phases, the difference between their space groups is associated with changes of $\mathrm{SiF}_{6}$ positions, which have already been described.

One can see that the difference between $\left(\mathrm{NH}_{4}\right)_{3} \mathrm{SiF}_{7}$ and $\left(\mathrm{NH}_{4}\right)_{3} \mathrm{GeF}_{7}$ is not only in the number and the sequence character $\left(\mathrm{G}_{3} \leftrightarrow \mathrm{G}_{4} \leftrightarrow \mathrm{G}_{5}\right)$ of phase transitions. Phase transition $P 4 / m b m \leftrightarrow P a \overline{3}$ in $\left(\mathrm{NH}_{4}\right)_{3} \mathrm{GeF}_{7}$ is reconstructive and cannot be analysed by group-theoretical methods while $P 4 / \mathrm{mbm} \leftrightarrow P 2_{1} / c$ transformation in $\left(\mathrm{NH}_{4}\right)_{3} \mathrm{SiF}_{7}$ can be described in this way. It should be noted that $\mathrm{K}_{3} \mathrm{SiF}_{7},{ }^{23} \mathrm{Rb}_{3} \mathrm{SiF}_{7},{ }^{24}$ and $\mathrm{Cs}_{3} \mathrm{GeF}_{7}{ }^{25}$ also have the $P 4 / \mathrm{mbm}$ phase at room temperature, while $\mathrm{Tl}_{3} \mathrm{SiF}_{7}{ }^{26}$ crystallizes in the $P \overline{3} 1 c$ space group, but nothing is known about their phase transitions.

All patterns from $133 \mathrm{~K}$ to $303 \mathrm{~K}$ were treated in a similar way and the temperature dependence of cell parameters $a, b, c$ (Fig. 2S(a) $\dagger$ ), cell volume $V$ (Fig. $2 \mathrm{~S}(\mathrm{~b}) \dagger$ ) and angles $\alpha, \beta, \gamma$ (Fig. 2S(c) †) were plotted.

Further details of the crystal structures of $\mathrm{G}_{1}, \mathrm{G}_{2}, \mathrm{G}_{3}$ and $\mathrm{G}_{5}$ phases may be obtained from Fachinformationszentrum Karlsruhe, 76344 Eggenstein-Leopoldshafen, Germany (fax: (+49)7247-808-666; E-mail: crystdata@fiz-karlsruhe.de; http:// www.fiz-karlsruhe.de/request_for_deposited_data.html on quoting the deposition numbers: CSD 432220; 432221; 432222 and 432223 , respectively).

\section{Conclusions}

Single crystals of silicon double salt $\left(\mathrm{NH}_{4}\right)_{3} \mathrm{SiF}_{7}=$ $\left(\mathrm{NH}_{4}\right)_{2} \mathrm{SiF}_{6} \cdot \mathrm{NH}_{4} \mathrm{~F}=\left(\mathrm{NH}_{4}\right)_{3}\left[\mathrm{SiF}_{6}\right] \mathrm{F}$ were grown, and we should recognize that the history of the compound goes back, in fact, more than 200 years. Davy observed tetragonal prisms, which were evidently $\left(\mathrm{NH}_{4}\right)_{3} \mathrm{SiF}_{7}$, in accordance with the tetragonal structure of this compound. We studied this compound by different methods. Calorimetric measurements revealed the succession of four reversible phase transitions below room temperature: $T_{1}=263 \pm 1 \mathrm{~K} ; T_{2}=198 \pm 1 \mathrm{~K} ; T_{3}=194 \pm 1 \mathrm{~K} ; T_{4}=$ $170 \pm 1 \mathrm{~K}$, and an absence of transformation into the $P m \overline{3} m$ phase up to decomposition. It was found that the application of uniaxial pressure does not change the orientation of the four-fold axis of $\left(\mathrm{NH}_{4}\right)_{3} \mathrm{SiF}_{7}$, similar to $\left(\mathrm{NH}_{4}\right)_{3} \mathrm{GeF}_{7},{ }^{11}$ which is in agreement with the fact that they are isostructural at room temperature. Therefore, both $\left(\mathrm{NH}_{4}\right)_{3} \mathrm{SiF}_{7}$ and $\left(\mathrm{NH}_{4}\right)_{3} \mathrm{GeF}_{7}$ differ from $\left(\mathrm{NH}_{4}\right)_{3} \mathrm{TiF}_{7}$ in which the high-pressure parent phase $P m \overline{3} m$ is attainable.

The polarization-optical studies showed lowering of symmetry during phase transitions at $T_{1}$ and $T_{2}$, similar to that observed in $\left(\mathrm{NH}_{4}\right)_{3} \mathrm{GeF}_{7}$. Further cooling $\left(\mathrm{NH}_{4}\right)_{3} \mathrm{SiF}_{7}$ revealed the existence of a complicated sequence of crystal symmetry 
changes with the appearance of triclinic $P \overline{1}\left(\mathrm{G}_{4}\right)$ and new monoclinic $P 12_{1} / c 1\left(G_{5}\right)$ phases. The large rotation angles of the indicatrix at $G_{4} \leftrightarrow G_{5}$ phase transition is associated with the 'proper' ferroelastic transitions when a parameter of transition $\delta$ is linearly related to the shear component of the spontaneous deformation $\delta \sim x_{5}$.

Joint XRD and optical analysis allowed us to solve and refine crystal structures of the $G_{1}, G_{2}, G_{3}$, and $G_{5}$ phases, suggest a model of the $\mathrm{G}_{4}$ phase and define the sequence of symmetry transformations: $P 4 / \mathrm{mbm}(Z=2)\left(\mathrm{G}_{1}\right) \leftrightarrow \operatorname{Pbam}(Z=4)$ $\left(\mathrm{G}_{2}\right) \leftrightarrow P 2_{1} / c(Z=4)\left(\mathrm{G}_{3}\right) \leftrightarrow P \overline{1}(Z=4)\left(\mathrm{G}_{4}\right) \leftrightarrow P 2_{1} / c(Z=8)\left(\mathrm{G}_{5}\right)$. Indeed, the sequence of the first three phases of $\left(\mathrm{NH}_{4}\right)_{3} \mathrm{SiF}_{7}$ coincides with that for $\left(\mathrm{NH}_{4}\right)_{3} \mathrm{GeF}_{7}$. Then a significant difference arises between them: $\left(\mathrm{NH}_{4}\right)_{3} \mathrm{GeF}_{7}$ undergoes a reconstructive phase transition to $\mathrm{Pa} \overline{3}$, but $\left(\mathrm{NH}_{4}\right)_{3} \mathrm{SiF}_{7}$ undergoes two phase transitions, which can be described by group-theoretical methods. The lowest-temperature phases in $\left(\mathrm{NH}_{4}\right)_{3} \mathrm{MF}_{7}(\mathrm{M}=$ $\mathrm{Si}, \mathrm{Ge})$ have similar cell parameters, and it seems that all $\mathrm{NH}_{4}$ groups are fully ordered in them. Therefore, the driving force of all phase transitions in $\left(\mathrm{NH}_{4}\right)_{3} \mathrm{MF}_{7}$ can be associated with the emergence of $\mathrm{N}-\mathrm{H} \cdots \mathrm{F}$ hydrogen bonds, because the value of $\mathrm{N} \cdots \mathrm{F}$ contacts decreases at phase transition under cooling. Suggested order-disorder processes are in accordance with the large values of entropy change.

The final scheme of phase transitions in $\left(\mathrm{NH}_{4}\right)_{3} \mathrm{SiF}_{7}$, including irreducible representations and corresponding order parameters, can be written as:

$$
\begin{aligned}
& \mathrm{P} 4 / \mathrm{mbm} \stackrel{M_{1}-\oplus M_{4}^{-}\left(\eta_{1}, \eta_{2}\right)}{\longleftrightarrow} \mathrm{Pbam}^{M_{1}-\oplus M_{4}-\left(\eta_{1}, \eta_{2}\right) \oplus M_{5}{ }^{-}(\xi, \xi)}
\end{aligned}
$$

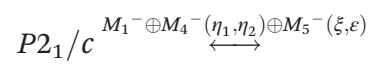

$$
\begin{aligned}
& P \overline{1}^{M_{1}^{-} \oplus M_{4}^{-}\left(\eta_{1}, \eta_{2}\right) \oplus M_{5}^{-}(\xi, \xi) \oplus Z_{1}^{+}(\delta)} P 2_{1} / c .
\end{aligned}
$$

In spite of the fact that the $P m \overline{3} m$ parent phase cannot be obtained under heating/pressure, the final scheme of phase transitions referred to the cubic phase can be expressed as:

$$
\begin{aligned}
& \operatorname{Pm} \overline{3} m \stackrel{M_{3}^{+}(\alpha, 0,0)}{\longleftrightarrow} P 4 / \mathrm{mbm}^{X_{5}+\left(0, \beta_{2}, 0,0, \beta_{5}, 0\right)} \\
& \operatorname{Pbam} \stackrel{X_{5}{ }^{+}\left(0, \beta_{2}, 0,0, \beta_{5}, \beta_{6}\right)}{\longrightarrow} P 2_{1} / c \stackrel{X_{5}^{+}\left(\beta_{1}, \beta_{2}, 0,0, \beta_{5}, \beta_{6}\right)}{\longrightarrow} \\
& P \overline{1} \stackrel{X_{5}^{+}\left(0, \beta_{5}, \beta_{3}, \beta_{4}, 0, \beta_{6}\right)}{\longleftrightarrow} P 2_{1} / c \text {. }
\end{aligned}
$$

\section{Acknowledgements}

The reported study was partially supported by RFBR, research project no. 15-02-02009a.

\section{Notes and references}

1 N. Laptash and I. Maslennikova, IOP Conf. Ser.: Mater. Sci. Eng., 2016, 112, 012024, DOI: 10.1088/1757-899X/112/1/ 012024 .
2 N. M. Laptash and L. N. Kurilenko, RU Patent, 2306546, 2007.

3 L. N. Kurilenko, N. M. Laptash, E. B. Merkulov and V. Yu. Glushchenko, Electron J. "Investigated in Russia", 2002, 130/021011, 1465-1471 http://zhurnal.ape.relarn.ru/ articles/2002/130.pdf.

4 N. M. Laptash and L. N. Kurilenko, RU Patent, 2157523, 2000.

5 A. M. Abdel-Rehim, J. Therm. Anal., 1997, 48, 177-202.

6 G. Meyer, Z. Anorg. Allg. Chem., 2008, 634, 201-222.

7 C. Plitzko and G. Meyer, Z. Anorg. Allg. Chem., 1996, 622, 1646-1650.

8 M. C. Marignac, Ann. Mines, 1859, 15, 221-290.

9 J. Davy, Philos. Trans. R. Soc. London, 1812, 102, 352-369.

10 J. L. Hoard and M. B. Williams, J. Am. Chem. Soc., 1942, 64, 633-637.

11 S. V. Mel'nikova, M. S. Molokeev, N. M. Laptash and S. V. Misyul, Dalton Trans., 2016, 45, 5321-5327.

12 M. S. Molokeev, S. V. Misyul, I. N. Flerov and N. M. Laptash, Acta Crystallogr., Sect. B: Struct. Sci., 2014, 70, 924-931.

13 I. N. Flerov, M. S. Molokeev, N. M. Laptash, A. A. Udovenko, E. I. Pogoreltsev, S. V. Mel'nikova and S. V. Misyul, J. Fluorine Chem., 2015, 178, 86-92.

14 E. I. Pogoreltsev, E. V. Bogdanov, A. V. Kartashev, M. S. Molokeev, I. N. Flerov and N. M. Laptash, Ferroelectrics, 2016, 501(1), 20-25.

15 S. V. Mel'nikova, E. I. Pogoreltsev, I. N. Flerov and N. M. Laptash, J. Fluorine Chem., 2014, 165, 14-19.

16 E. I. Pogoreltsev, I. N. Flerov, A. V. Kartashev, E. V. Bogdanov and N. M. Laptash, J. Fluorine Chem., 2014, 168, 247-250.

17 J. E. Ricci and J. A. Skarulis, J. Am. Chem. Soc., 1951, 73, 3618-3627.

18 Bruker AXS TOPAS V4, General profile and structure analysis software for powder diffraction data - User's Manual, Bruker AXS, Karlsruhe, Germany, 2008.

19 O. V. Kovalev, Representation of Crystallographic Space Groups, CRC Press, 1993.

20 S. C. Miller and W. F. Love, Tables of Irreducible Representations of the Space Groups and CoRepresentations of Magnetic Space Groups, Pruett Press Boulder, Colorado, 1967.

21 B. V. Beznosikov and K. S. Aleksandrov, J. Struct. Chem., 2002, 43, 798-801.

22 A. M. Glazer, Acta Crystallogr., Sect. B: Struct. Crystallogr. Cryst. Chem., 1972, 28, 3384-3392.

23 D. L. Deadmore and W. F. Bradley, Acta Crystallogr., 1962, 15, 186-189.

24 B. Hofmann and R. Hoppe, Z. Anorg. Allg. Chem., 1979, 458, 151-162.

25 F. Averdunk and R. Hoppe, J. Less-Common Met., 1989, 146, 137-145.

26 V. A. Shreider, I. M. Vol'pin and Y. E. Gorbunova, Russ. Chem. Bull., 1988, 37, 831-835. 